\title{
Snapshot of Computational Thinking in Turkey: A Critique of 2019 Bebras Challenge
}

\author{
Filiz KALELİOĞLU ${ }^{1}$, Dilek DOĞAN²${ }^{2}$, Yasemin GÜLBAHAR ${ }^{2}$ \\ ${ }^{1}$ Education Faculty, Baskent University, Turkey \\ ${ }^{2}$ Educational Sciences Faculty, Ankara University, Turkey \\ e-mail:filizk@baskent.edu.tr,dilek.dogan@ankara.edu.tr,gulbahar@ankara.edu.tr
}

Received: March 2021

\begin{abstract}
This study aims to provide a deeper understanding about the Bebras tasks, which is one of the computational thinking (CT) unplugged activities, in terms of age level, task category, and CT skills. Explanatory sequential mixed method was adopted in the study in order to collect data according to the research questions. The participants of the study were 113,653 school students from different age levels. Anonymous data was collected electronically from the Turkey 2019 Bebras challenge. Factor analysis was employed to reveal the construct validity to determine how accurately the tool measured the abstract psychological characteristics of the participants. In addition, the item discrimination index was calculated to measure how discriminating the items in the challenge were. Qualitative data gathered through the national Bebras workshop was analysed according to content analysis. The findings highlighted some interesting points about the implications of the Bebras Challenge for Turkey, which are discussed in detail. Furthermore, common problems of Bebras tasks are identified and possible suggestions for improvement are listed.
\end{abstract}

Keywords: Bebras, Computational thinking, Challenge on Informatics, Assessment.

\section{Introduction}

The increasing use of technology in recent years has resulted in people solving problems more effectively and efficiently through the use of technology. This paradigm shift in modern society raises the importance of teaching the concepts of informatics and computational thinking at an early age. Being information, media, computer, and technology literate is not enough, as society needs people who are computational thinkers as well as problem solvers across virtually all of today's professions. Since young generations were born into and are maturing within a world surrounded by technological tools and innovations, thinking computationally has gained significant importance in order for people to be able to cope with the rapid changes and developments faced in different aspects of everyday life (McClelland \& Grata, 2018). Thus, educators are advised to integrate certain important computational thinking concepts into different disciplines, 
and to start talking about these concepts and principles beginning with early childhood (Shute et al., 2017).

Newell et al. (1967) stated that since studies on plants were considered as botany, studies on animals are termed as zoology, studies on stellar observations are called astronomy; therefore, it seems appropriate that we address studies involving computers and computing as computer science. Comer et al. (1989) defined the 'computer science' discipline as systematic studies on the algorithmic process of information transformation and explanation. The concept of 'informatics' was later introduced by Denning (2005) as an information-oriented concept used in Europe instead of 'computer science'. The concept of informatics is defined as a mathematical discipline related to information (Rapaport, 2017), which indicates the application and working areas that emerge at the intersection of mathematical approach and information and communication (informatics) technologies.

On the other hand, 'computational thinking' was defined as the problem-solving processes that focus on system design and the understanding of human behaviour based on the founding concepts of computer science (Barr et al., 2011; Liu \& He, 2014; Papert, 1980; Wing, 2006; Wing \& Stanzione, 2016). In other words, solving problems with computers, technological or other tools, logically organising and analysing data, presenting data supported by models or simulations, automating solutions in the context of algorithmic thinking, identifying, analysing and implementing the best solutions, as well as adapting and generalising solutions according to different situations are all example processes that can be expected from a computational thinker, according to a definition put forward by the Computer Science Teachers Association and the International Society for Technology in Education (2011).

Hence, the concept of computational thinking has been introduced to the Turkish curriculum in 2012 and revised in 2016. In light of this information, this study aims to investigate the computational thinking skills of 113,653 school students from different age levels in Turkey. For this purpose, Bebras tasks' were used to understand the relationship between students' age level, task category, and CT skills. Implementation and evaluation of the Bebras Challenge in Turkey is the uniqueness of this study about computational thinking which consisted of a high number of participation from different age levels. In this context, firstly, the concepts of computational thinking, Bebras International Informatics, and the Computational Thinking Challenge were explained.

\subsection{Computational Thinking: Definition and Theoretical Framework}

Computational thinking, as a concept, first emerged in the period when machines were first able to calculate. In those days, it was used solely for hardware and became part of our language based on it being 'computational' thinking. However, with the developments in technological tools and processes, this concept has broadened and has become much more comprehensive (Denning \& Tedre, 2019).

When computers were first developed, machines could only perform calculations, but then the operations covered by these calculations developed and began to be per- 
formed with much larger numbers and also successively. With the advent of languages that control machines, machines have succeeded in processing series of complex instructions. In this way, computers that process commands on a line-by-line basis according to machine language have succeeded in performing more complex operations with the advent of programming languages. Preliminary studies determined which steps should be employed in solving problems in order to be able to perform complex operations through programming, and thus, the process steps we now refer to as 'algorithm design' and the concepts of algorithmic thinking first emerged.

With the increasingly complex operations of algorithms, the need arose to manage these problems by dividing them into smaller parts. This concept, which we consider as 'decomposition', enables the process steps that perform certain operations to be written separately from the main programs. Thus, by dividing complex problems into sub-problems, structures that we call 'function' have become continuously accessible. Today, the structure created by these ready-to-use functions is called a 'library'.

Over time, programming languages have continued to evolve, with visual programming languages having emerged as programs able to draw graphics in line with the increases seen in display and graphic features, as well as in text-based software. The concept of the 'object' emerged specifically to control structures on a computer screen. Object-oriented programming has enabled many environments and processes to be defined and changed as a result of the 'abstraction' of different properties and processes. The screen you are currently probably looking at actually consists of numerous windows, i.e., layers, and its content, function, and display properties vary according to the program it is associated with (Computing at School, 2019). Programs and programming have continued to advance and evolve, with graphics beginning to be encoded and interpreted differently, that is, in the manipulation of images on a computer screen. By developing the 'pattern recognition' as a skill, programmers have become able to interpret the results of health screening such as with X-ray, Magnetic Resonance Imaging (MRI), and Computed Tomography (CT) scans, as well as systems such as fingerprint and facial recognition (Shute et al., 2017).

While computers perform operations such as calculating, drawing graphics, and calling functions, their primary operation is 'data processing'. When we visualise data, create a graphical image, view a digital photograph, or connect to a website via the Internet, all of these processes are achieved through data processing and data management (Angevine, 2018; Angevine et al., 2017; Grover, 2018; Shute et al., 2017). Sometimes the algorithms and programs written may not work as expected or may return incorrect or seemingly invalid results even though they functionally appear to work. In this case, there is usually a syntax or logic error within the algorithm, and this error must therefore be identified and eliminated in order for the program to produce the correct result. This process, referred to as 'debugging', allows the software to reach its targeted result by eliminating errors within its algorithms (McCauley et al., 2008).

As it is understood from sub-skills of computational thinking, computational thinking includes a set of concepts and practices that help in formulating problems and their solutions in different disciplines (Mannila et al., 2014). From a disciplinary perspective, Denning and Tedre (2021) specified computational thinking as "the mental skills 
and practices for designing computations that get computers to do jobs for us, and for explaining and interpreting the world in terms of information processes" (p. 365). Similarly, Perkovic, Settle, Hwang, and Jones (2010) argued computational thinking as intellectual and reasoning skills to apply computational techniques or computer applications to the problems and projects in any discipline. As students begin to think in different and new ways, computational thinking has the potential to contribute to students' problemsolving skills and abilities significantly (Yadav et al., 2014).

In summary, computational thinking skills, which are based on problem solving and logical reasoning, and involve areas such as abstraction, data processing, algorithm design, decomposition, and pattern recognition are important skills that need to be integrated into all educational courses, and especially into mathematics, the sciences, and project-based teaching processes using interdisciplinary approaches (Kalelioğlu et al., 2016). As stated by many researchers, computational thinking skills can be taught not only through block-based teaching applications, educational games, and physical programming approaches, but also through 'computer science unplugged' activities, i.e., teaching and learning without the use of computers (Bell et al., 1998; Weinberg, 2013). In this context, one common application for computer science unplugged activities that has reached the international dimension is the annual Bebras Challenge.

\subsection{Bebras: International Informatics and Computational Thinking Challenge}

Bebras (https://www.bebras.org/) is a challenge aimed at computational thinking and computer science, with school-age student participants required to think about related concepts and processes whilst solving set tasks and problems. It is an international event that is organised simultaneously across more than 50 countries since its initial foundation by Valentina Dagienè in Lithuania in 2004.

The main purpose of the challenge is to introduce students to algorithmic, logical, and operational informatics practices within an entertaining climate in order to encourage them to learn and master thinking computationally (Dagienè \& Futschek, 2008). The challenge involves students aged between 6 and 18 years old who are expected to solve 15 set tasks within a period of 45 minutes, with the tasks arranged in groups of five under three difficulty levels as easy, medium, and hard. The Bebras tasks are also categorised under five topics as; 'Algorithms and programming', 'Data, data structures, and representations, 'Computer processes and hardware', 'Communication and networking', and finally 'Interactions, systems, and society', and the five dimensions of CT as; 'Abstraction', 'Algorithmic thinking', 'Decomposition', 'Evaluation', and 'Generalisation'.

The Bebras tasks are prepared by representatives of each of the contributing countries, with each country then selecting tasks from a central task pool which they then translate to their native language for implementation. First, each country is required to prepare 5-8 tasks according to a detailed template where the question, details about the question (age group, CT dimension, CS concepts, etc.) and an explanation of the solution are provided in detail. Bebras community collaborates through a central content 
management system (CMS) so the countries are requested to upload their tasks to this system. After that, the "Task Committee" moves these tasks to a review system where the review process takes place. Each task is assigned at least 3 reviewers and they rate the quality of the tasks according to pre-defined criteria besides providing feedback. After reviews are finished, the countries are requested to update their tasks according to the feedback of reviewers prior to the international Bebras workshop. International Bebras Workshop is held every year around May-June and the main purpose is to decide on which tasks should be used next year besides other decisions. For this reason, each country is requested to be presented in this workshop by at least one representative. Working groups (at least 10 groups) are formed and assigned Bebras tasks. During the workshop, each group works on tasks and comes up with proposed tasks for next years' event. These accepted tasks are placed under the relevant folder in the system so that each country can select the tasks and translate them into their own languages. Hence, each Bebras task is rated by some 5-10 people and long discussions are carried about the appropriateness and difficulty level of the task to the specified age group, content, visual, interactivity, etc. during the workshop.

The Bebras activity has been scientifically developed, with positive findings obtained in various research studies conducted in different countries (https://www . bebras . org). The challenge targets more and more participants each year, and continues to provide different benefits for the students who participate

\subsection{The Purpose of the Study and Research Questions}

In this context, the current research study aims to provide a deeper understanding of the tasks used in a Bebras challenge in terms of age level, task category, and the CT skills they involve. As such, the current study aims to reveal answers to the following research questions:

1. To what extent are the difficulty levels of questions aligned between the experts of the Bebras community and the results of item analysis?

2. What is the grade-point average (GPA) of the Bebras participants by grade level?

3. What is the level of computational thinking skills of Bebras participants in Turkey according to their age?

4. What type of questions in the Bebras challenge vary according to the participants' age level in terms of performance?

5. What are the opinions of computing experts with regards to the alignment of CT concepts and practices with existing knowledge in order to solve Bebras tasks?

\section{Research Method}

Explanatory sequential mixed method was adopted in the current study in order to collect data according to the research questions. Accordingly, qualitative data was collected after the quantitative data were collected and analysed. 
Table 1

Demographic information of participants by grade level and gender

\begin{tabular}{lrrr}
\hline Grade & \multicolumn{2}{c}{ Gender } & \multirow{2}{*}{ Total } \\
\cline { 2 - 3 } & Female & \multicolumn{1}{c}{ Male } & \\
\hline 3rd-4th & 13,648 & 15,344 & 28,992 \\
5th-6th & 24,883 & 27,043 & 51,926 \\
7th-8th & 9,959 & 11,235 & 21,194 \\
Preparatory: 9th-10th & 5,919 & 5,622 & 11,541 \\
Total & 54,409 & 59,244 & 113,653 \\
\hline
\end{tabular}

\subsection{Participants}

For the quantitative data, the participants of the study were 113,653 students from Turkey who participated in the Turkey 2019 Bebras Challenge. A demographic summary of the participants is presented in Table 1.

For the qualitative data of the study, six field experts took part in this research, two of whom are academic faculty members with experience in preparing questions for the Bebras challenge. The other four field experts are Information and Communication Technologies (ICT) teachers.

\subsection{Data Collection}

The data collected for each participant was stored electronically on a Moodle database (an open-source Learning Management System), with the Bebras challenge (known as 'Bilge Kunduz' in Turkey) conducted online over a 1-week period. The duration of the challenge is 45 minutes, which is ended automatically by the system according to the time that the participant starts the activity. Participants who answer multiple-choice questions and believe that they have answered all of the questions, may opt to finish the activity at any point within the 45-minute limit. During the challenge, the participants may continue any activity from where they left off when re-entering the system should they encounter any technical problems such as loss of Internet connection or a power outage. Following completion of the challenge, the participants (and their teachers) are given the opportunity to view the answers and their score. Also, they can view details of the correct answers to each question.

Following completion of the activity, the participants' data was obtained for analysis in spreadsheet form via the Moodle platform. After analysis of the quantitative data, qualitative data were then collected from the six field experts (two faculty members and four teachers), using a low discrimination index via a Google form that included four open-ended questions. 


\subsection{Data Analysis}

In the study, exploratory factor analysis was conducted in order to reveal the construct validity, so as to determine how accurately the Bebras challenge as a tool measures the abstract psychological characteristics of the participants. In addition, the item discrimination index was calculated in order to measure how discriminating the items were in the challenge. The analysis of the quantitative data was conducted using the $\mathrm{R}$ program.

In the study, reliability analysis was performed according to the Classical Test Theory (CTT) for the 15-question Bebras challenge used to measure the student participants' computational thinking skills. According to the CTT, the discrimination value (r-value) calculated as the correlation coefficient takes a value between -1 and +1 . Questions with a low r-value should be examined, and then removed from the test if necessary (Crocker \& Algina, 1986). According to the CTT, item selection is based on pointbiserial correlation. Accordingly, questions with an item difficulty index value of .19 or lower should not be included in the test or should be changed. Questions with an item difficulty index of between .20 and .29 should be partially corrected, whilst questions with an item difficulty index value between .30 and .39 do not require any correction, and questions with an item difficulty index value of .40 or above can be immediately included in the test.

The qualitative data gathered from the field experts in the current study were analysed through content analysis. The data was first prepared for analysis, then the themes were defined based on the study's research questions, and finally the data were coded according to the themes.

\section{Findings}

In this section, the findings obtained from analysing the collected data are presented according to the study's research questions.

\subsection{Difficulty Levels of Questions}

Factor analysis was conducted in order to reveal the structure and to explain the measurement and the factors of the 15-item Bebras measurement tool, which consists of easy, medium, and hard difficulty level questions prepared to measure the computational thinking skills of third- and fourth-grade students. It was observed that the common variance of the only factor defined in the items varied between .319 and .657 . The instrument's single factor explained $44 \%$ of the total variance. According to Classical Test Theory, none of the questions required removal from the test (see Table 2).

The 15-item measurement tool prepared to measure fifth- and sixth-grade students' computational thinking skills used the same structure. The common variance of the sin- 
Table 2

Factor analysis and Classic Test Theory results of $3^{\text {rd }}$ and $4^{\text {th }}$ grade students' questions by R programme

\begin{tabular}{|c|c|c|c|c|c|}
\hline \multirow{2}{*}{$\begin{array}{l}\text { Question } \\
\text { Difficulty } \\
\text { Level }\end{array}$} & \multirow[t]{2}{*}{ Question Name } & \multicolumn{2}{|l|}{ Factor Analysis } & \multicolumn{2}{|c|}{ Classic Test Theory } \\
\hline & & $\begin{array}{l}\text { Common Factor } \\
\text { Variance }\end{array}$ & $\begin{array}{l}\text { Rotated Factor } \\
\text { Loads in factor } 1\end{array}$ & $\begin{array}{l}\text { Item } \\
\text { Difficulty }\end{array}$ & $\begin{array}{l}\text { Point } \\
\text { Biserial }\end{array}$ \\
\hline \multirow[t]{5}{*}{ Easy } & Birthday Cake & .517 & .695 & .631 & .476 \\
\hline & Arranging Balls & .536 & .681 & .278 & .453 \\
\hline & Candy Shop & .319 & .825 & .807 & .490 \\
\hline & Colourful route & .487 & .717 & .553 & .534 \\
\hline & Box of Balls & .548 & .672 & .420 & .505 \\
\hline \multirow[t]{5}{*}{ Medium } & Scratch Art Paper & .568 & .657 & .484 & .460 \\
\hline & Traveling in Space & .657 & .585 & .230 & .287 \\
\hline & Bath at the Lido & .531 & .685 & .577 & .479 \\
\hline & Image Representation & .587 & .642 & .407 & .471 \\
\hline & Golfer Bebras & .585 & .644 & .312 & .416 \\
\hline \multirow[t]{5}{*}{ Hard } & Wood Allergies & .651 & .591 & .356 & .384 \\
\hline & Bridges and Islands & .643 & .598 & .338 & .348 \\
\hline & Wizard Bibrax & .598 & .634 & .344 & .447 \\
\hline & Special Towers & .591 & .640 & .392 & .436 \\
\hline & Colourful Chinese character & .635 & .604 & .348 & .399 \\
\hline
\end{tabular}

gle factor varied between .489 and .658 , which explained $39 \%$ of the total variance. According to CTT, the 'Ants in Swamp' question should be eliminated from the fifth- and sixth-graders' test (see Table 3).

The 15-item measurement tool prepared to measure the seventh and eighth grade students' computational thinking skills used the same structure. It was observed that the common variance of the single factor varied between .508 and .690, and explained 38\% of the total variance. According to CTT, the 'A Glass Slipper Buying Shoes' question should be eliminated from the seventh- and eighth-graders' test (see Table 4).

The 15-item measurement tool prepared to measure the preparatory class, ninth-, and 10th-grade students' computational thinking skills used the same structure. It was observed that the common variance of the single factor defined in the items varied between .482 and .633 , explaining $42 \%$ of the total variance. According to CTT, the 'A Glass Slipper Buying Shoes' question should be eliminated from the test for preparatory class, ninth-, and 10th-grade students (see Table 5).

When the results of the factor analysis are examined, it can be seen that the rotated factor loads in the Factor 1 values of the 15-item test prepared according to each grade level are greater than .30. However, it is understood that the 'Ants in Swamp' question for the 5th and 6th grades and the 'A Glass Slipper Buying Shoes' question for 7th and 8th grades, preparatory class, and the 9th and 10th grades should be excluded from the test according to CTT-based analysis. The learners' performance based on the question difficulty levels and the experts' opinions about each questions were shared in detail. 
Table 3

Factor analysis and Classic Test Theory results of $5^{\text {th }}$ and $6^{\text {th }}$ grade students' questions by R programme

\begin{tabular}{|c|c|c|c|c|c|}
\hline \multirow{2}{*}{$\begin{array}{l}\text { Question } \\
\text { Difficulty } \\
\text { Level }\end{array}$} & \multirow[t]{2}{*}{ Question Name } & \multicolumn{2}{|l|}{ Factor Analysis } & \multicolumn{2}{|c|}{ Classic Test Theory } \\
\hline & & $\begin{array}{l}\text { Common Factor } \\
\text { Variance }\end{array}$ & $\begin{array}{l}\text { Rotated Factor } \\
\text { Loads in factor } 1\end{array}$ & $\begin{array}{l}\text { Item } \\
\text { Difficulty }\end{array}$ & $\begin{array}{l}\text { Point } \\
\text { Biserial }\end{array}$ \\
\hline \multirow[t]{5}{*}{ Easy } & Bath at the Lido & .529 & .686 & .598 & .498 \\
\hline & Golfer Bebras & .607 & .627 & .341 & .404 \\
\hline & Image Representation & .601 & .632 & .390 & .461 \\
\hline & Scratch Art Paper & .562 & .662 & .521 & .476 \\
\hline & Traveling in Space & .613 & .622 & .267 & .359 \\
\hline \multirow[t]{5}{*}{ Medium } & Wood Allergies & .658 & .585 & .353 & .375 \\
\hline & Bridges and Islands & .636 & .604 & .365 & .365 \\
\hline & Special Towers & .594 & .637 & .406 & .446 \\
\hline & Colourful Chinese character & .610 & .625 & 372 & .434 \\
\hline & Wizard Bibrax & .590 & .641 & .361 & .457 \\
\hline \multirow[t]{5}{*}{ Hard } & Digital Number & .655 & .588 & .285 & .379 \\
\hline & The Feast & .683 & .563 & .257 & .273 \\
\hline & Ants in Swamp & .650 & .592 & .182 & .198 \\
\hline & Message from the Elder Beavers & .489 & .715 & .595 & .544 \\
\hline & Visits & .643 & .597 & .185 & .258 \\
\hline
\end{tabular}

Table 4

Factor analysis and Classic Test Theory results of 7th and 8th grade students' questions by R programme

\begin{tabular}{|c|c|c|c|c|c|}
\hline \multirow{2}{*}{$\begin{array}{l}\text { Question } \\
\text { Difficulty } \\
\text { Level }\end{array}$} & \multirow[t]{2}{*}{ Question Name } & \multicolumn{2}{|l|}{ Factor Analysis } & \multicolumn{2}{|c|}{ Classic Test Theory } \\
\hline & & Common Factor & Rotated Factor & Item & $\begin{array}{l}\text { Point } \\
\text { Piseriol }\end{array}$ \\
\hline \multirow[t]{5}{*}{ Easy } & Wood Allergies & .664 & .580 & .370 & .379 \\
\hline & Bridges and Islands & .632 & .607 & .401 & .419 \\
\hline & Special Towers & .629 & .609 & .510 & .466 \\
\hline & Colourful Chinese character & .604 & .629 & .445 & .478 \\
\hline & Wizard Bibrax & .580 & .648 & .457 & .499 \\
\hline \multirow[t]{5}{*}{ Medium } & Digital Number & .610 & .625 & .375 & .467 \\
\hline & The Feast & .644 & .596 & .262 & .317 \\
\hline & Ants in Swamp & .608 & .626 & .198 & .285 \\
\hline & Message from the Elder Beavers & .508 & .701 & .692 & .518 \\
\hline & Visits & .624 & .613 & .263 & .366 \\
\hline \multirow[t]{5}{*}{ Hard } & Bee Hive & .642 & .599 & .202 & .249 \\
\hline & A Glass Slipper Buying Shoes & .690 & .557 & .158 & .149 \\
\hline & Cakes and Neighbours & .642 & .598 & .182 & .211 \\
\hline & Beaver Network & .662 & .581 & .235 & .307 \\
\hline & Aircraft Scheduling & .619 & .617 & .296 & .383 \\
\hline
\end{tabular}


Table 5

Factor analysis and Classic Test Theory results of preparatory class, $9^{\text {th }}$ and $10^{\text {th }}$ grade students' questions by R programme

\begin{tabular}{|c|c|c|c|c|c|}
\hline \multirow{2}{*}{$\begin{array}{l}\text { Question } \\
\text { Difficulty } \\
\text { Level }\end{array}$} & \multirow[t]{2}{*}{ Question Name } & \multicolumn{2}{|l|}{ Factor Analysis } & \multicolumn{2}{|c|}{ Classic Test Theory } \\
\hline & & $\begin{array}{l}\text { Common Factor } \\
\text { Variance }\end{array}$ & $\begin{array}{l}\text { Rotated Factor } \\
\text { Loads in factor } 1\end{array}$ & $\begin{array}{l}\text { Item } \\
\text { Difficulty }\end{array}$ & $\begin{array}{l}\text { Point } \\
\text { Biseriaa }\end{array}$ \\
\hline \multirow[t]{5}{*}{ Easy } & Digital Number & .551 & .670 & .528 & .536 \\
\hline & The Feast & .584 & .645 & .318 & .390 \\
\hline & Ants in Swamp & .609 & .625 & .282 & .418 \\
\hline & Message from the Elder Beavers & .482 & .720 & .750 & .503 \\
\hline & Visits & .583 & .646 & .431 & .490 \\
\hline \multirow[t]{5}{*}{ Medium } & Bee Hive & .594 & .637 & .221 & .302 \\
\hline & A Glass Slipper Buying Shoes & .633 & .606 & .142 & .158 \\
\hline & Cakes and Neighbours & .608 & .626 & .187 & .258 \\
\hline & Beaver Network & .578 & 649 & .307 & .413 \\
\hline & Aircraft Scheduling & .574 & .653 & .398 & .472 \\
\hline \multirow[t]{5}{*}{ Hard } & Sawmill & .569 & .657 & .327 & .442 \\
\hline & Classification Yard & .587 & .643 & .252 & .326 \\
\hline & Willows and poplars & .613 & .622 & .162 & .210 \\
\hline & Railway Electrification & .566 & .659 & .268 & .405 \\
\hline & Greener Flight Routes & .592 & .638 & .302 & .410 \\
\hline
\end{tabular}

\subsection{Grade-point Average (GPA) of Participants by Grade Level}

The total score' average of the participants shows that the female students, except for those in the preparatory class, ninth-, and 10th-grade, scored generally higher than their male counterparts (see Fig. 1).

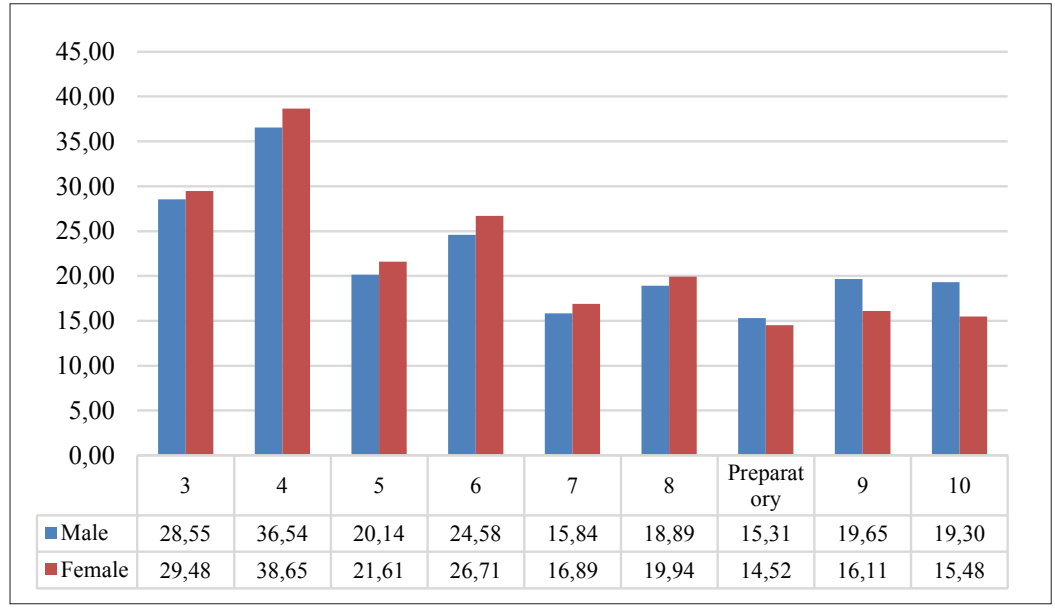

Fig. 1 Grade-point average of participants by grade level and gender 


\subsection{Level of Computational Thinking Skills in Different Age Groups in Turkey}

Bebras' tasks are designed according to different age groups (arranged by school grade in the Turkish context), ranging from age 7 to 17 years old in Turkey. The Bebras challenge promotes problem-solving skills and informatics concepts including the ability to design algorithms, abstraction, decomposition, pattern recognition, and evaluation. The same questions were asked to students grouped by their school grade, with the 3 rd and 4th grades, the 5th and 6th grades, and the 7th and 8th grades, and those in the preparatory, 9th and 10th grades. According to Table 6, the number of correct answers was found to be higher for those students in the lower grades when answering the same easy level questions at the 3rd and 4th grades and also at the 5th and 6th grades and at the 7 th and 8 th grades.

In the easy question category for third- and fourth graders, the percentage of participants who correctly answered the 'Arranging Balls' question that requires knowledge of the algorithm and sorting concept was higher at the fourth grade. The percentage of participants who answered 'Golfer Bebras' incorrectly those that require abstraction skills is decreasing in the fifth and sixth grades. In the seventh and eighth grades, the percentage of correct answers at the 'Special Tower' question, which does not require abstraction skill, is higher than the other questions that require abstraction skill. While the ninth and 10th grades require abstraction skills, the percentage of the participants to

Table 6

The answer percentages of the easy difficulty questions by grade level

\begin{tabular}{|c|c|c|c|c|c|c|c|c|c|c|c|c|c|c|c|c|}
\hline$\frac{\mathbb{\pi}}{\tilde{\sigma}}$ & 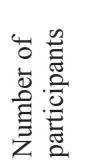 & 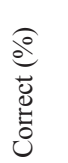 & 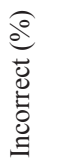 & $\frac{e^{\frac{\partial}{d}}}{\frac{\vec{c}}{m}}$ & $\begin{array}{l}\frac{0}{0} \\
\stackrel{0}{0} \\
0 \\
0\end{array}$ & 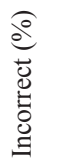 & $\frac{e^{e}}{\frac{y}{n}}$ & $\underbrace{0}_{0}$ & 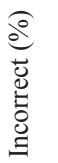 & 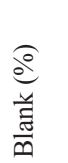 & 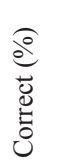 & 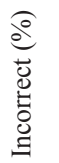 & $\frac{e^{\frac{\partial}{d}}}{\frac{\vec{t}}{m}}$ & 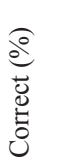 & 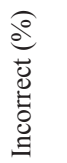 & 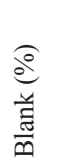 \\
\hline & & \multicolumn{3}{|c|}{ Birthday Cake } & \multicolumn{3}{|c|}{ Arranging Balls } & \multicolumn{3}{|c|}{ Candy Shop } & \multicolumn{3}{|c|}{ Colourful route } & \multicolumn{3}{|c|}{ Box of Balls } \\
\hline 3 & 14,929 & 59.8 & 32.1 & 8.1 & 24.6 & 66.1 & 9.3 & 77.3 & 14.6 & 8.1 & 50.4 & 40.8 & 8.8 & 38.7 & 50.0 & 11.3 \\
\hline \multirow[t]{2}{*}{4} & 14,072 & 66.6 & 27.4 & 6.0 & 31.2 & 61.9 & 6.8 & 84.2 & 9.9 & 6.0 & 60.4 & 33.2 & 6.4 & 45.5 & 45.8 & 8.6 \\
\hline & & \multicolumn{3}{|c|}{ Bath at the Lido } & \multicolumn{3}{|c|}{ Golfer Bebras } & \multicolumn{3}{|c|}{$\begin{array}{l}\text { Image } \\
\text { Representation }\end{array}$} & \multicolumn{3}{|c|}{ Scratch Art Paper } & \multicolumn{3}{|c|}{ Traveling in Space } \\
\hline 5 & 24,255 & 58.1 & 33.1 & 8.8 & 31.3 & 59.4 & 9.3 & 37.8 & 48.9 & 13.4 & 50.1 & 41.0 & 8.9 & 24.6 & 64.5 & 11.0 \\
\hline \multirow[t]{2}{*}{6} & 27,662 & 61.3 & 30.6 & 8.2 & 36.4 & 55.2 & 8.4 & 40.0 & 47.3 & 12.7 & 53.8 & 38.0 & 8.2 & 28.5 & 61.5 & 10.0 \\
\hline & & \multicolumn{3}{|c|}{ Wood Allergies } & \multicolumn{3}{|c|}{$\begin{array}{l}\text { Bridges and } \\
\text { Islands }\end{array}$} & \multicolumn{3}{|c|}{ Special Towers } & \multicolumn{3}{|c|}{$\begin{array}{l}\text { Colourful Chinese } \\
\text { character }\end{array}$} & \multicolumn{3}{|c|}{ Wizard Bibrax } \\
\hline 7 & 14,752 & 37.7 & 48.1 & 14.2 & 39.5 & 50.9 & 9.6 & 50.3 & 41.5 & 8.2 & 44.1 & 44.4 & 11.5 & 45.5 & 43.1 & 11.4 \\
\hline \multirow[t]{2}{*}{8} & 6,442 & 35.6 & 45.0 & 19.5 & 41.3 & 45.1 & 13.6 & 52.8 & 36.3 & 10.9 & 45.4 & 40.0 & 14.6 & 46.1 & 38.8 & 15.0 \\
\hline & & \multicolumn{3}{|c|}{ Digital Number } & \multicolumn{3}{|c|}{ The Feast } & \multicolumn{3}{|c|}{ Ants in Swamp } & \multicolumn{3}{|c|}{$\begin{array}{l}\text { Message from the } \\
\text { Elder Beavers }\end{array}$} & \multicolumn{3}{|l|}{ Visits } \\
\hline $\begin{array}{l}\text { Prepa- } \\
\text { ratory }\end{array}$ & 1,278 & 52.5 & 30.4 & 17.1 & 29.6 & 47.1 & 23.3 & 25.5 & 63.2 & 11.3 & 77.5 & 10.7 & 11.8 & 40.1 & 43.7 & 16.1 \\
\hline 9 & 5,835 & 54.9 & 31.2 & 13.9 & 32.0 & 48.7 & 19.4 & 28.1 & 62.0 & 9.9 & 78.3 & 12.2 & 9.5 & 44.1 & 43.9 & 12.0 \\
\hline 10 & 4,428 & 50.0 & 36.7 & 13.3 & 32.4 & 51.2 & 16.4 & 29.2 & 60.8 & 10.0 & 70 & 19.0 & 11.0 & 42.7 & 45.4 & 12.0 \\
\hline
\end{tabular}


answer the question is higher for in the 'Digital Number' and 'Message from the Elder Beavers' questions (see Table 6).

According to the questions at the medium difficulty level, it was observed that the third and fourth grade participants generally made mistakes in Golfer Bebras, which require both abstraction skills. The skill of abstraction is required for all the medium difficulty questions for the fifth and sixth grades and the majority of the participants answered these questions incorrectly. All medium difficulty questions for the seventh and eighth grade participants require the skill of abstraction. However, it was observed that there was a higher percentage of correct answers for 'Message from the Elder Beavers' questions, which require both abstraction and pattern-recognition skills when compared to the other questions. The medium difficulty questions of all of the preparatory, ninth-, and 10th-grade participants require abstraction skills, and most of the participants gave incorrect answers to these questions (see Table 7).

All of the questions in the hard question category at all grade levels require abstraction skills. The questions that required both abstraction skills and pattern-recognition skills at the 3rd and 4th grade and also at the 5th and 6th grade levels were answered correctly more than the other questions.

According to the questions at the hard difficulty level, all questions except for 'Message from the Elder Beavers' were answered incorrectly at all grade levels. All of these questions require abstraction, decomposition, and pattern-recognition skills (see Table 8).

Table 7

The answer percentages of the medium difficulty questions by grade level

\begin{tabular}{|c|c|c|c|c|c|c|c|c|c|c|c|c|c|c|c|c|}
\hline 胥 & 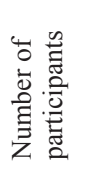 & $\begin{array}{l}\underbrace{0}_{0} \\
0 \\
0 \\
0\end{array}$ & 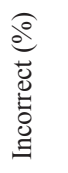 & 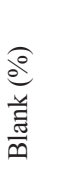 & 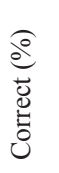 & 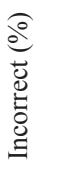 & 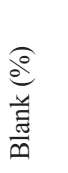 & $\begin{array}{l}e_{0}^{0} \\
0 \\
0 \\
0 \\
0\end{array}$ & 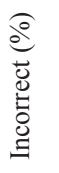 & 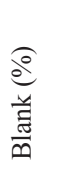 & 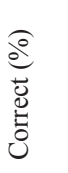 & 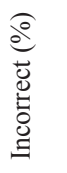 & 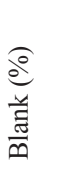 & 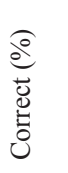 & 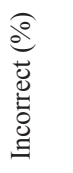 & 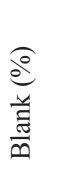 \\
\hline & & \multicolumn{3}{|c|}{ Scratch Art Paper } & \multicolumn{3}{|c|}{ Traveling in Space } & \multicolumn{3}{|c|}{ Bath at the Lido } & \multicolumn{3}{|c|}{$\begin{array}{l}\text { Image } \\
\text { Representation }\end{array}$} & \multicolumn{3}{|c|}{ Golfer Bebras } \\
\hline 3 & 14,929 & 46.2 & 45.2 & 8.7 & 22.2 & 67.0 & 10.7 & 53.3 & 38.2 & 8.6 & 37.9 & 49.6 & 12.5 & 28.2 & 62.7 & 9.1 \\
\hline & 14,072 & 50.7 & 42.7 & 6.6 & 23.8 & 68.1 & 8.1 & 62.2 & 31.7 & 6.1 & 43.6 & 46.9 & 9.5 & 34.4 & 59.0 & 6.6 \\
\hline & & \multicolumn{3}{|c|}{ Wood Allergies } & \multicolumn{3}{|c|}{$\begin{array}{l}\text { Bridges and } \\
\text { Islands }\end{array}$} & \multicolumn{3}{|c|}{ Special Towers } & \multicolumn{3}{|c|}{$\begin{array}{l}\text { Colourful Chinese } \\
\text { character }\end{array}$} & \multicolumn{3}{|c|}{ Wizard Bibrax } \\
\hline 5 & 24,255 & 34.1 & 52.2 & 13.7 & 35.3 & 53.7 & 11.0 & 37.8 & 53.1 & 9.1 & 35.2 & 51.9 & 12.9 & 33.9 & 53.6 & 12.5 \\
\hline & 27,662 & 36.2 & 50.2 & 13.5 & 3 & 52.2 & 10.3 & 43.0 & 48.3 & 8 & .9 & 49.0 & 12.1 & 37.9 & 50.7 & 11.4 \\
\hline & & \multicolumn{3}{|c|}{ Digital Number } & \multicolumn{3}{|c|}{ The Feast } & \multicolumn{3}{|c|}{ Ants in Swamp } & \multicolumn{3}{|c|}{$\begin{array}{l}\text { Message from the } \\
\text { Elder Beavers }\end{array}$} & \multicolumn{3}{|l|}{ Visits } \\
\hline 7 & 14,752 & 36.3 & 49.4 & 14.4 & 26.2 & 59.5 & 14.3 & 19.3 & 71.9 & 8.7 & 69.2 & 21.7 & 9.1 & 25.8 & 62.9 & 11.4 \\
\hline \multirow[t]{2}{*}{8} & 6,442 & 40.4 & 43.0 & 16.7 & 26.3 & 53.6 & 20.1 & 20.9 & 67.1 & 12.0 & 68.9 & 19.2 & 11.9 & 27.7 & 56.8 & 15.5 \\
\hline & & \multicolumn{3}{|c|}{ Bee Hive } & \multicolumn{3}{|c|}{$\begin{array}{l}\text { A Glass Slipper } \\
\text { Buying Shoes }\end{array}$} & \multicolumn{3}{|c|}{$\begin{array}{l}\text { Cakes and } \\
\text { Neighbours }\end{array}$} & \multicolumn{3}{|c|}{ Beaver Network } & \multicolumn{3}{|c|}{$\begin{array}{l}\text { Aircraft } \\
\text { Scheduling }\end{array}$} \\
\hline $\begin{array}{l}\text { Prepa- } \\
\text { ratory }\end{array}$ & 1,278 & 19.4 & 61.0 & 19.6 & 11.8 & 64.6 & 23.6 & 17.4 & 64.6 & 18.0 & 27.6 & 51.3 & 21.1 & 41.5 & 42.4 & 16.1 \\
\hline 9 & 5,835 & 21.8 & 63.5 & 14.8 & 13.1 & 67.2 & 19.7 & 17.8 & 67.2 & 15.1 & 30.6 & 51.3 & 18.1 & 40.6 & 44.9 & 14.5 \\
\hline 10 & 4,428 & 23.3 & 62.8 & 13.9 & 16.3 & 67.9 & 15.8 & 20.3 & 66.9 & 12.9 & 31.7 & 53.2 & 15.1 & 38.3 & 49.7 & 12.0 \\
\hline
\end{tabular}


Table 8

The answer percentages of the hard difficulty questions by grade level

\begin{tabular}{|c|c|c|c|c|c|c|c|c|c|c|c|c|c|c|c|c|}
\hline 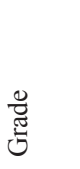 & 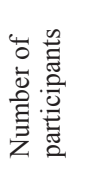 & $\begin{array}{l}\underbrace{0}_{0} \\
0 \\
0 \\
0 \\
0 \\
0\end{array}$ & 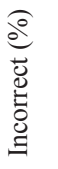 & $\frac{e^{o}}{\frac{y}{d}}$ & $\frac{\int_{0}^{0}}{d_{0}^{0}}$ & 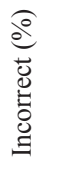 & $\begin{array}{l}\frac{\partial}{d} \\
\frac{y}{n} \\
\frac{\vec{d}}{n}\end{array}$ & $\frac{\int_{0}^{0}}{\substack{0 \\
0}}$ & 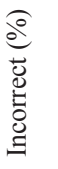 & 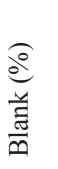 & 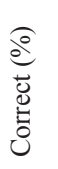 & 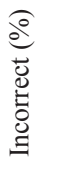 & $\frac{e^{o}}{\frac{y}{n}}$ & 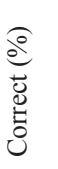 & 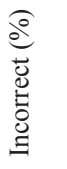 & $\begin{array}{l}\frac{\partial}{d} \\
\frac{\sqrt{d}}{m}\end{array}$ \\
\hline & & \multicolumn{3}{|c|}{ Wood Allergies } & \multicolumn{3}{|c|}{$\begin{array}{l}\text { Bridges and } \\
\text { Islands }\end{array}$} & \multicolumn{3}{|c|}{ Wizard Bibrax } & \multicolumn{3}{|c|}{ Special Towers } & \multicolumn{3}{|c|}{$\begin{array}{l}\text { Colourful } \\
\text { Chinese character }\end{array}$} \\
\hline 3 & 14,929 & 33.4 & 54.0 & 12.6 & 32.2 & 57.3 & 10.5 & 31.7 & 56.7 & 11.6 & 37.8 & 53.0 & 9.2 & 32.1 & 55.7 & 12.2 \\
\hline \multirow[t]{2}{*}{4} & 14,072 & 37.9 & 52.4 & 9.7 & 35.5 & 56.6 & 7.9 & 37.3 & 53.8 & 9.0 & 40.6 & 52.6 & 6.8 & 7.6 & 53.0 & 9.3 \\
\hline & & \multicolumn{3}{|c|}{ Digital Number } & \multicolumn{3}{|c|}{ The Feast } & \multicolumn{3}{|c|}{ Ants in Swamp } & \multicolumn{3}{|c|}{$\begin{array}{l}\text { Message from the } \\
\text { Elder Beavers }\end{array}$} & \multicolumn{3}{|c|}{ Visits } \\
\hline 5 & 24,255 & 26.8 & 56.6 & 16.6 & 25.4 & 61.1 & 13.5 & 18.8 & 71.3 & 9.9 & 57.4 & 32.1 & 10.6 & 16.9 & 71.6 & 11.5 \\
\hline \multirow[t]{2}{*}{6} & 27,662 & 29.9 & 54.4 & 15.6 & 25.9 & 60.4 & 13.7 & 17.6 & 73.1 & 9.3 & 61.3 & 28.9 & 9.8 & 20.0 & 68.6 & 11.4 \\
\hline & & \multicolumn{3}{|c|}{ Bee Hive } & \multicolumn{3}{|c|}{$\begin{array}{l}\text { A Glass Slipper } \\
\text { Buying Shoes }\end{array}$} & \multicolumn{3}{|c|}{$\begin{array}{l}\text { Cakes and } \\
\text { Neighbours }\end{array}$} & \multicolumn{3}{|c|}{ Beaver Network } & \multicolumn{3}{|c|}{$\begin{array}{l}\text { Aircraft } \\
\text { Scheduling }\end{array}$} \\
\hline 7 & 14,752 & 20.3 & 66.7 & 12.9 & 16.4 & 68.1 & 15.5 & 18.4 & 70.2 & 11.3 & 23.1 & 61.0 & 15.9 & 29.3 & 59.0 & 11.7 \\
\hline \multirow[t]{2}{*}{8} & 6,442 & 20.0 & 61.8 & 18.2 & 14.5 & 64.0 & 21.6 & 17.9 & 66.3 & 15.8 & 24.7 & 55.3 & 20.0 & 30.1 & 53.4 & 16.5 \\
\hline & & \multicolumn{3}{|c|}{ Sawmill } & \multicolumn{3}{|c|}{ Classification Yard } & \multicolumn{3}{|c|}{$\begin{array}{l}\text { Willows and } \\
\text { poplars }\end{array}$} & \multicolumn{3}{|c|}{$\begin{array}{l}\text { Railway } \\
\text { Electrification }\end{array}$} & \multicolumn{3}{|c|}{$\begin{array}{l}\text { Greener Flight } \\
\text { Routes }\end{array}$} \\
\hline $\begin{array}{l}\text { Prepa- } \\
\text { ratory }\end{array}$ & 1,278 & 26.8 & 42.8 & 30.4 & 22.3 & 43.0 & 34.7 & 14.7 & 63.2 & 22.1 & 21.8 & 47.5 & 30.8 & 25.3 & 55.8 & 18.9 \\
\hline 9 & 5,835 & 32.9 & 43.2 & 23.9 & 24.3 & 46.6 & 29.1 & 15.4 & 66.9 & 17.7 & 26.4 & 47.2 & 26.5 & 31.2 & 54.1 & 14.7 \\
\hline 10 & 4,428 & 34.2 & 47.7 & 18.1 & 27.3 & 51.4 & 21.3 & 17.6 & 67.4 & 15.0 & 28.8 & 51.6 & 19.6 & 30.3 & 56.4 & 13.4 \\
\hline
\end{tabular}

\subsection{Learners' Performance According to Question Difficulty Type:} Easy, Medium, Hard

The 'Wood Allergies', 'Bridges and Islands', 'Wizard Bibrax', 'Special Towers', and 'Colourful Chinese Character' questions were categorised as hard for the 3rd and 4th grade, of medium difficulty for the 5th and 6th grades, and easy for the 7th and 8th grades. Most of these questions were answered incorrectly by participants at all age levels. These questions include abstraction, decomposition, modelling and simulation, algorithms, evaluation. In addition, the 'Colourful Chinese Character' question also includes pattern-recognition skills (see Table 9).

The 'Message from the Elder Beavers', 'Ants in Swamp', 'Digital Number', 'Visits', and 'The Feast' questions were categorised as hard for the 3rd and 4th grade, medium difficulty for the 5th and 6th grade, and easy for the 7 th and 8 th grade. The 'Ants in Swamp' item is an abstraction question, and most of the participants answered this question incorrectly. The average of the correct answers for all questions except for the 'Message from the Elder Beavers' question was found to be low. Although this question required abstraction skills, the visual provided was thought to help the participants in solving the problem. As the grade level increased, the percentage of correct answers to these questions also mostly increased (see Table 10). 
Table 9

Same questions categorised as hard for 3rd-4th grade, medium for 5th-6th grade, easy for 7 th -8 th grade

\begin{tabular}{|c|c|c|c|c|c|c|c|c|c|c|c|c|c|c|c|}
\hline \multirow[b]{2}{*}{$\underset{\tilde{T}}{\mathbb{Z}}$} & \multicolumn{3}{|c|}{ Wood Allergies } & \multicolumn{3}{|c|}{$\begin{array}{l}\text { Bridges and } \\
\text { Islands }\end{array}$} & \multicolumn{3}{|c|}{ Wizard Bibrax } & \multicolumn{3}{|c|}{ Special Towers } & \multicolumn{3}{|c|}{$\begin{array}{l}\text { Colourful Chinese } \\
\text { character }\end{array}$} \\
\hline & 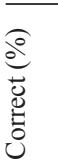 & 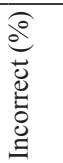 & 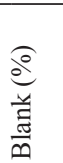 & 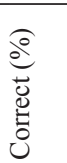 & 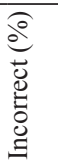 & 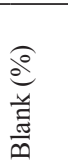 & 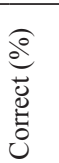 & 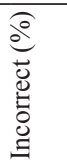 & 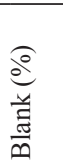 & 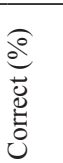 & 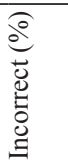 & 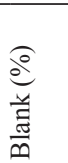 & $\begin{array}{l}\underbrace{0}_{0} \\
\stackrel{0}{0} \\
\stackrel{0}{0}\end{array}$ & 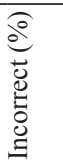 & 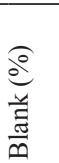 \\
\hline 3 & 33.4 & 54.0 & 12.6 & 32.2 & 57.3 & 10.6 & 31.7 & 56.7 & 11.6 & 37.8 & 53.0 & 9.2 & 32.1 & 55.7 & 12.2 \\
\hline 4 & 37.9 & 52.4 & 9.7 & 35.5 & 56.6 & 7.9 & 37.3 & 53.7 & 9.0 & 40.6 & 52.6 & 6.8 & 37.6 & 53.0 & 9.3 \\
\hline 5 & 33.7 & 51.5 & 13.5 & 34.9 & 53.1 & 10.8 & 33.5 & 53.0 & 12.4 & 37.3 & 52.4 & 9.0 & 34.8 & 51.3 & 12.8 \\
\hline 6 & 36.2 & 50.2 & 13.5 & 37.5 & 52.2 & 10.3 & 37.9 & 50.7 & 11.4 & 43.0 & 48.3 & 8.6 & 38.9 & 49.0 & 12.1 \\
\hline 7 & 37.7 & 48.1 & 14.2 & 39.5 & 50.9 & 9.6 & 45.5 & 43.1 & 11.4 & 50.3 & 41.5 & 8.2 & 44.1 & 44.4 & 11.5 \\
\hline 8 & 35.6 & 45.0 & 19.5 & 41.3 & 45.1 & 13.6 & 46.1 & 38.8 & 15.0 & 52.8 & 36.3 & 10.9 & 45.4 & 40.0 & 14.6 \\
\hline
\end{tabular}

Table 10

Same questions categorised as hard for 3rd-4th grade, medium for 5 th -6 th grade, easy for 7 th -8 th grade

\begin{tabular}{|c|c|c|c|c|c|c|c|c|c|c|c|c|c|c|c|}
\hline \multirow[b]{2}{*}{ 莡 } & \multicolumn{3}{|c|}{$\begin{array}{l}\text { Message from the } \\
\text { Elder Beavers }\end{array}$} & \multicolumn{3}{|c|}{ Ants in Swamp } & \multicolumn{3}{|c|}{ Digital Number } & \multicolumn{3}{|c|}{ Visits } & \multicolumn{3}{|c|}{ The Feast } \\
\hline & 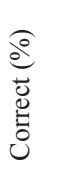 & 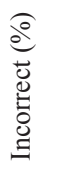 & 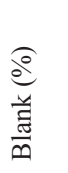 & 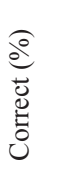 & 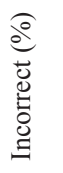 & $\begin{array}{l}\frac{\partial}{d} \\
\frac{a}{a} \\
\frac{a}{n}\end{array}$ & 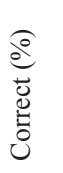 & 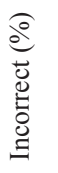 & $\frac{\stackrel{0}{e}}{\frac{\tilde{a}}{0}}$ & $\underbrace{0}_{0}$ & 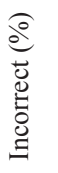 & 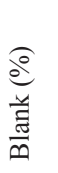 & $\underbrace{0}_{0}$ & $\begin{array}{l}\underset{0}{0} \\
\stackrel{0}{0} \\
\stackrel{0}{0} \\
0 \\
\Xi\end{array}$ & 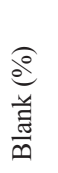 \\
\hline 5 & 56.7 & 31.7 & 10.5 & 18.6 & 70.4 & 9.8 & 26.4 & 56.0 & 16.4 & 16.7 & 70.8 & 11.3 & 25.1 & 60.3 & 13.4 \\
\hline 6 & 61.3 & 28.9 & 9.8 & 17.6 & 73.1 & 9.3 & 29.9 & 54.4 & 15.6 & 20.0 & 68.6 & 11.4 & 25.9 & 60.4 & 13.7 \\
\hline 7 & 69.2 & 21.7 & 9.1 & 19.3 & 71.9 & 8.7 & 36.3 & 49.4 & 14.4 & 25.8 & 62.9 & 11.4 & 26.2 & 59.5 & 14.3 \\
\hline 8 & 68.9 & 19.2 & 11.9 & 20.9 & 67.1 & 12.0 & 40.4 & 43.0 & 16.7 & 27.7 & 56.8 & 15.5 & 26.3 & 53.6 & 20.1 \\
\hline $\begin{array}{l}\text { Prepa- } \\
\text { ratory }\end{array}$ & 77.5 & 10.7 & 11.8 & 25.5 & 63.2 & 11.3 & 52.5 & 30.4 & 17.1 & 26.8 & 42.8 & 30.4 & 26.8 & 43.7 & 16.1 \\
\hline 9 & 78.3 & 12.2 & 9.5 & 28.1 & 62.0 & 9.9 & 54.9 & 31.2 & 13.9 & 32.9 & 43.2 & 23.9 & 44.1 & 43.9 & 12.0 \\
\hline 10 & 70.0 & 19.0 & 11.0 & 29.2 & 60.8 & 10.0 & 50.0 & 36.7 & 13.3 & 34.2 & 47.7 & 18.1 & 42.7 & 45.4 & 12.0 \\
\hline
\end{tabular}

\subsection{Experts' Opinions about the Tasks}

The opinions of the experts regarding the tasks were gathered. The knowledge and skills required to resolve the assigned tasks are emphasised within the framework of four basic questions.

- What do students need to know in order to solve the task? (knowledge level)

- What skills do students need to know/use in order to solve the task? (skill level)

- Which problem-solving strategies should students use in order to solve the task?

- What kind of adjustments/changes could be made in order for students to better understand the task/ problem? 
The 'Arranging Balls' task was categorised as easy for third- and fourth-graders and included the concepts of algorithms and sorting. In order to solve this problem, students need to create an algorithm, group, model, apply trial and error, and to think spatially. In order to make the task more understandable, one of the experts suggested that the description was made more revealing, whilst another said that the statement sentence should be rearranged and that the task could include an example image. Another of the experts stated that it would be better suited to primary school students if the task appeared on at least one screen; supporting that idea, one of the experts stated that starting and ending situations should be displayed side by side on the same screen.

In the 'Traveling in Space' task, which was categorised as being of medium difficulty for third- and fourth-graders, the students do not need to know anything conceptually at the level of knowledge, but they should focus on skills such as trying different ways, trial and error, reading visually, testing, eliminating incorrect paths, choosing the most suitable solution, and defining the problem. All of the experts said that the problem statement and explanation were unclear and needed to be rewritten. Moreover, one of the experts stated that the shapes were complex, and the directions of the arrows varied considerably, and that the example sentence was overly complex and confusing.

In the 'Visit' task, which was categorised as hard for fifth- and sixth-graders, the students may need to know graph theory, and may also need to employ skills such as sequential thinking, parallel-processing capability, finding alternative solutions, and eliminating unnecessary paths. The experts said that some parts of the question were unclear, and one stated that symbolising relatives' houses and toll roads using different colours would help to improve clarity.

The 'Digital Number' task was categorised as hard for fifth- and sixth-graders, with students needing to know how numbers are displayed digitally and the concept of LED. While coding and encoding can be used in problem solving, the experts also focused on modelling and spatial thinking. In terms of improving the task, one of the experts said that the students may not know about LEDs and diodes and may therefore have difficulty in understanding the expression 'three LEDs in three lines', and that orientation could be improved using arrows. One of the experts stated that it should be explained that the table in the example is coloured according to frequencies, whilst two of the experts stated that the down arrow shown in the table was thought to be confusing. Another of the experts stated that the question wording was too complex and that there was too much text, that it may be difficult to see and make sense of by students with colour blindness, that it was difficult to understand from the example table, and that it may be difficult for students to imagine which corresponds to which number.

The 'Feast' task was categorised as hard for fifth- and sixth-graders, with students requiring knowledge of reading both a digital and analogue clock, as well as understanding words such as subtasks, pipelining, and microprocessor. It was observed that skills such as parallel processing, decomposition, and pattern recognition would be necessary to solve the task, and that students may face difficulty with time displayed us- 
ing the 24-hour format. Two of the experts stated that the task may have been perceived as difficult because the question was too long, and that the clock image can perhaps be used to facilitate the students' understanding. Another of the experts stated that explanations about the task needed to be made more understandable.

The 'Ants in Swamp' task was categorised as hard for fifth- and sixth-grade students, as they needed to know concepts such as optimisation, network flow, and possess skills such as parallel thinking, whilst keeping in mind reading algorithms, and also modelling to complete the task. No additional suggestions were made by the experts regarding potential improvements; however, one questioned why the word 'maximum' was used when participants exit at the same time.

The 'Bee Hive' task was categorised as hard for seventh- and eighth-graders as students need to be familiar with concepts such as median, L1 distance, Manhattan distance, coordinate, rows and columns, which are keywords in the question design. Students would also require skills such as reading and interpreting the table, as well as the trial and error approach whilst solving the problem. With regards to making the task more understandable, one of the experts stated that the question was given twice; as in the explanation and also the question part, and that such repetition was inadvisable. Another of the experts stated that the question sentence appeared difficult, and that students would not understand the term 'possible place'.

The 'Glass Slipper Buying Shoes' task was categorised as hard for seventh- and eighth-graders. In the experts' opinions, they focused on the required knowledge of the difference between large and small numbers. While the logical reasoning and trial and error approaches were found to be appropriate to solve the problem, the experts mentioned that the students must start from the middle point and reach the correct result through the elimination of available options. In order to make the task more understandable, one of the experts suggested shortening the task, while another explained that the concept of $\mathrm{N}$ may not be understood, but could be more understandable if examples were provided.

The 'Cakes and Neighbours' task was categorised as hard for seventh- and eighthgrade students, as they would need to know the concept of variables and order of operations. Whilst solving the problem, students would need to employ strategies such as decomposition, parallel processing, questioning, mathematical calculation, and also modelling. Only one of the experts stated that the task was very difficult to understand, and that it would require a considerable amount of time and effort to find a solution.

The 'Beaver Network' task was categorised as hard for seventh- and eighth-grade students, as they would need to be familiar with concepts such as network, junction, router, and conditions. Also, skills such as sorting, selection, parallel thinking, analysis, reverse data processing, interpretation skills, modelling the previous step, and trial and error could be used to solve the problem. One of the experts stated that the entrance and exit locations of the network were unclear, and also how long it would take to encounter the beavers. In supporting that view, another of the experts stated that it would be useful to provide additional information as the two beavers could appear at the same time as well as at different times. Another of the experts stated that there was misinformation 
about where the beavers of the same colour went, and that this could present a problem for some students.

The 'Aircraft Scheduling' task was categorised as hard for seventh- and eighthgraders, as students would need to use skills such as planning, sequencing, reading and interpreting the table, and defining the problem, although they would not require any conceptual knowledge. One of the experts stated that the question text and graphics were too lengthy and difficult to understand. Another expert suggested that a different expression could be used instead of the \# sign in the examples, whilst one expert stated that for a student who had not previously flown in an aircraft, and had no knowledge of flight codes, the table used for the problem could be difficult to read and interpret. There may also have been problems in the question arising from the lack of this information.

The 'Classification Yard' task was categorised as a hard task for ninth- and 10thgraders, as they would need to know concepts such as classification and stack sorting, and also have experience in practice decomposition, divide and conquer, and sorting skills. The experts suggested certain improvements in order to make the task more understandable. In support of that, some of the other experts explained that there were unacceptable words used in the question such as 'individual wagon' and 'classification area'.

The 'Willows and Poplars' task was categorised as hard as the students would need to know concepts such as logical operators and conditions, and would require skills such as reverse thinking and modelling. The experts stated that there was a considerable amount of text, but no visual support in the task. Two of the experts stated that it was a really hard task, and that the explanation was inaccurate.

Finally, the 'Railway Electrification' task was categorised as hard for ninth- and 10th-graders, and that it was considered to be related to programming, required knowledge of concepts such as variables and loops, and required skills such as modelling and analysis. Two of the experts stated that the visual provided for the task was not very clear, and that the table which presented the algorithm could have been described more clearly. One of the experts suggested that it could be better understood if pseudocode had been used in blocks instead of code.

\section{Results and Discussion}

This study was aimed to understand of relationship between students' CT skills, their age level, task category of Bebras challenge. Based on the results of both the qualitative and quantitative research, when the same questions were asked at different grade levels, the percentage of correct answers was found to increase according to the participants' increasing grade level. In tasks that require abstraction skills, especially those categorised as hard, were correctly answered at a very low for all grade level groups. In line with the findings of the current research, it has been emphasised in the literature that there is a strong tendency for students to move from understanding concrete to abstract concepts as their age increases (Lutz et al., 2018). Both the process 
of understanding and answering questions and the actual conceptual understanding necessary to answer questions can be complex when they are of an abstract nature (Ahmed \& Pollitt, 1999).

The participating students in Turkey 2019 Bebras Challenge did not show a high level of performance with tasks related to 'algorithms, data, computer systems, or communication'. In the Bebras challenge, tasks relating to algorithms and data representation are the most prevalent. This situation was also similarly expressed in a study conducted with multiple nationalities by Izu et al. (2017), in which the authors stated that the data indicated that the challenge mainly addressed algorithms and data.

There are several reasons why students may see these tasks as difficult and therefore unable to resolve them, and the reasons why students respond less to these tasks appear to be due to three reasons. As stated by the experts participating in the current research, first it may be caused by situations related to the structure of the challenge, such as not understanding the tasks, the levels of the tasks, or having no prior experience in such a challenge. As stated by Gülbahar et al. (2020), according to the results of their research, the reason for students' lower performance levels in the Bebras challenge was related to the tasks being of different types from the questions that the students were familiar with. The second reason relates to a lack of the conceptual knowledge required, which for Turkey is an issue related to the national curriculum. The concepts covered in the Bebras challenge tasks were officially introduced into the national educational programmes of Turkey in 2012, and were subsequently updated in 2016. However, the impact of this knowledge learning and the process of transitioning to this type of teaching and learning continues, and as time passes, students will also get more used to tackling such activities and thereby develop their computational thinking skills (Gülbahar et al., 2020). The third reason relates to a lack of problemsolving knowledge in using conceptual information.

When the relation of problem tasks and the area of informatics is evaluated; for algorithm categorised tasks, students should possess knowledge of programming skills and programming concepts (loop, variable, logic operators, parameters, conditions, etc.), and they should know how to apply problem-solving strategies such as divide and conquer, decomposition, sorting, scheduling, graph colouring, sorting, as well as trial and error. For tasks with a focus on data structures, not all students may know about concepts such as stack and LED, or have knowledge of coding and encoding processes. For tasks that focus on computer systems; subtasks, pipelining, microprocessors, parallel processing concepts and processes should be mastered, whilst for tasks related to communication, concepts such as network, junction, router, and conditions increase in significance. Therefore, in addition to including conceptual and practical knowledge related to these tasks in the curriculum, it is also important to teach problem-solving strategies to students in a context appropriate to the Bebras tasks. As stated by Dagienè and Stupurienè (2016), the Bebras challenge not only tests students in terms of informatics and CT concepts, it is also highly motivational for the learning of new informatics concepts, and to support the development of algorithmic thinking 
as well as computational thinking. Moreover, teachers should learn how to explain what lies behind Bebras tasks and to model the solutions of tasks to their students. Moreover, task difficulty level can also relate to the linguistic and structural properties of how a task is written and described (Ahmed \& Pollitt, 1999).

In addition, computational thinking and informatics concepts can be taught through the use of CS unplugged approaches, such as the example presented in the current study. The Bebras challenge not only provides students with good practice and thinking opportunities, but also provides teachers with exposure to different question types and solutions, and enables them to also practice how to teach such new concepts. Bebras tasks are not only used by researchers for scientific research purposes, but can also be utilised by teachers as part of their grading and evaluation. Web traffic analysis shows very clearly that the Bebras website is used by many students, teachers, and researchers (and maybe parents) throughout the whole year, and not just during the challenge week itself.

\section{Conclusion, Recommendations and Limitations}

The study is conducted based on the assumption that mathematical approach and informatics-oriented application processes reveal the intersecting fields of study between information and communication technologies and informatics, which is of significant importance as a skill required in modern life today. Moreover, the study was conducted in order to investigate the nature of the annual Bebras challenge from different perspectives, and also to provide suggestions for improvements to future implementations.

- According to the item analysis, the Bebras tasks were shown to be grade appropriate for the Turkish context.

- The results showed that the computational level of students at all grades were at a low level.

- Expected performance outcomes in terms of task difficulty levels were not observed, with no grade level group having performed higher in all the easy tasks and lower in the hard tasks.

- While the average achievement of the female students was higher at the high school level, the male students were slightly more successful than females in the other grade level groups.

By this study, it was also possible to reveal common problems in Bebras tasks. Thus, Bebras tasks could possibly be improved based on the following suggestions:

- Use visuals in each task.

- Keep reading text as short as possible.

- Use age-appropriate language and vocabulary.

- Make sure the question and visuals fit into a screen to avoid scrolling.

- Avoid repetition in the body of text, question, and visuals. 
- Include instructional tips (i.e. giving examples, explanations) for easy understanding of the visuals.

- Use alternative symbols or descriptions for color blinds.

Having revealed many scientific facts, this study had also some limitations. Since the data were collected from students who voluntarily participated in the Bebras challenge from one country, namely Turkey, the findings of the study cannot be generalized to other countries. Although the Bebras community has a quite agreement on the level and difficulty of the tasks, due to the Bebras tasks' nature of being cultural-sensitive, there are always different voices from various countries based on variations in curricula and school systems.

Each year, more teachers are showing interest in the Bebras challenge which all adds to enrich the experience of a greater number of students. It is clear that computational thinking skills should be integrated in some part of the activities in various courses in order to increase student performance, and in aiming to achieve this, computing teachers should focus more on activities that contain CT skills (Lonati, 2020). As a conclusion, it may be said that the Bebras challenge is welcomed by schools in Turkey with growing interest each year, and that this interest is likely to develop as more teachers realise the importance of this very specific thinking skill for the digital age. Hence, researchers will continue doing more in-depth research to observe the development of CT skills in different disciplines and age groups.

\section{References}

Ahmed, A., Pollitt, A. (1999, May). Curriculum Demands and Question Difficulty [Conference presentation]. IAEA Conference, Bled, Slovenia.

Angevine, C. (2018). Advancing Computational Thinking across K-12 Education. https://www.gettingsmart.com/2018/02/advancing-computational-thinking-across-k-12-education/

Angevine, C., Cator, K., Roschelle, J., Thomas, S.A., Waite, C., Weisgrau, J. (2017). Computational Thinking for a Computational World.

http://digitalpromise.org/wp-content/uploads/2017/12/dp-comp-thinking-v1r5.pdf

Barr, D., Harrison, J., Conery, L. (2011). Computational thinking: A digital age skill for everyone. Learning \& Leading with Technology, 38(6), 20-23.

Bell, T.C., Witten, I.H., Fellows, M.R. (1998). Computer Science Unplugged . . Off-Line Activities and Games for All Ages.

https://classic.csunplugged.org/wp-content/uploads/2015/01/unplugged-book-v1.pdf

Comer, D.E., Gries, D., Mulder, M.C., Tucker, A., Turner, A.J., Young, P.R. (1989). Computing as a discipline. Communications of the ACM, 32(1), 9-23.

Computing at School. (2019). Computational thinking: How do we think about problems so that computers can help? https://community. computingatschool.org.uk/files/8221/original.pdf

Crocker, L., Algina, J. (1986). Introduction to classical and modern test theory. Wadsworth Publishing Co Inc.

Dagienė, V., Stupurienė, G. (2016). Bebras - A sustainable community building model for the concept based learning of informatics and computational thinking. Informatics in Education, 15(1), 25-44.

Dagienè, V.,\& Futschek, G. (2008). Bebras international contest on informatics and computer literacy: criteria for good tasks. In R.T. Mittermeir and M.M. Syslo (Eds.), Lect. Notes in Computer Science. Informatics Education-Supporting Computational Thinking (pp. 28-39). Springer. 
Denning, P.J. (2005). Is computer science? Communications of the ACM, 48(4), 27-31.

Denning, P.J., Tedre, M. (2019). Computational Thinking. MIT Press.

Denning, P.J., Tedre, M. (2021). Computational Thinking: A Disciplinary Perspective. Informatics in Education, 20(3), 361-390.

Grover, S. (2018, February). The 5th 'C' of 21st Century Skills? Try Computational Thinking (not Coding). EdSurge. https://www.edsurge.com/news/2018-02-25-the-5th-c-of-21st-century-skillstry-computational-thinking-not-coding

Gülbahar, Y., Kalelioğlu, F., Doğan, D., Karataş, E. (2020). Bebras: A social approach for concept based learning of informatics and computational thinking. Ankara University Journal of Faculty of Educational Sciences (JFES), 53(1), 241-272.

International Society for Technology in Education. (2011). Computational Thinking in K-12 Education Leadership Toolkit. Computer Science Teacher Association.

https://id.iste.org/docs/ct-documents/ct-leadershipt-toolkit.pdf?sfvrsn=4

Izu, C., Mirolo, C., Settle, A., Mannila, L., Stupurienė, G. (2017). Exploring Bebras Tasks content and performance: A multinational study. Informatics in Education, 16(1), 39-59.

Kalelioğlu, F., Gülbahar, Y., Kukul, V. (2016). A framework for computational thinking based on a systematic research review. Baltic Journal of Modern Computing, 4(3), 583-596.

Liu, B., He, J. (2014). Teaching mode reform and exploration on the university computer basic based on computational thinking training in network environment. Proceedings of the 9th international Conference on Computer Science \& Education (ICCSE 2014), Canada, 59-62.

Lonati, V. (2020). Getting Inspired by Bebras Tasks. How Italian Teachers Elaborate on Computing Topics. Informatics in Education, 19(4), 669-699. DOI: 10.15388/infedu.2020.29

Lutz, C., Berges, M., Hafemann, J., Sticha, C. (2018). Piaget's cognitive development in Bebras tasks - a descriptive analysis by age groups. In: S.N. Pozdniakov \& V. Dagienè (Eds.), International Conference on Informatics in Schools: Situation, Evolution, and Perspectives (pp. 259-270). Springer.

Mannila, L., Dagienè, V., Demo, B., Grgurina, N., Mirolo, C., Rolandsson, L., Settle, A. (2014). Computational thinking in K-9 education. In: Proceedings of the Working Group Reports of the 2014 on Innovation \& Technology in Computer Science Education Conference, ITiCSE-WGR 2014, 1-29. ACM, New York.

McCauley, R., Fitzgerald, S., Lewandowski, G., Murphy, L., Simon, B., Thomas, L., Zander, C. (2008). Debugging: A review of the literature from an educational perspective. Computer Science Education, 18(2), 67-92.

McClelland, K., Grata, L.A. (2018). Review of the Importance of Computational Thinking in K-12. In: J.C. Kush \& C. Lester (Eds.), Proceedings of the eLmL 2018: The Tenth International Conference on Mobile, Hybrid, and On-line Learning (pp. 2-34). Red Hook.

Newell, A., Perlis, A. J., Simon, H. (1967). What is Computer Science? Science, 157(3795), 1373-1374.

Papert, S. (1980). Mindstorms: Children, computers, and powerful ideas. Basic Books.

Rapaport, W.J. (2017). What Is Computer Science? http://www.cse.buffalo.edu/ rapaport/Papers/whatiscsapa-20170127-edited.pdf

Perkovic, L., Settle, A., Hwang, S., Jones, J.A. (2010). Framework for Computational Thinking across the Curriculum. In: Proceedings of the Fifteenth Annual Conference on Innovation and Technology in Computer Science Education, ITICSE 2010, 123-127, NY, United States.

Shute, V.J., Sun, C., Asbell-Clarke, J. (2017). Demystifying computational thinking. Educational Research Review, 22, 142-158.

Weinberg, A.E. (2013). Computational thinking: An investigation of the existing scholarship and research [Unpublished doctoral dissertation]. Colorado State University.

Wing, J.M. (2006). Computational Thinking. Communications of The ACM, 49(3), 33-35.

Wing,J., Stanzione, D. (2016). Progress in computational thinking, and expanding the HPC community. Communications of the ACM, 59(7), 10-11.

Yadav, A., Mayfield, C., Zhou, N., Hambrusch, S., Korb, J.T. (2014). Computational thinking in elementary and secondary teacher education. ACM Transactions on Computing Education (TOCE), 14(1), 1-16. 
F. Kalelioğlu is an Associate Professor of Computer Education and Instructional at Education Faculty, Baskent University. Her research interests are mainly related to distance learning, e-learning, instructional design, the use of technology in education, and computer science education.

D. Doğan is a lecturer at the Department of Computer Education and Instructional Technology at Ankara University in Ankara, Turkey. Her research interests are in 3D multi-user virtual environments, virtual worlds, games, educational games, mobile learning, online learning environments, distance education, and the design of these learning environments.

Y. Gülbahar is a Professor at the Department of Computer Education and Instructional Technologies in the Faculty of Educational Sciences of Ankara University. She is currently working on computer science and information technology education, instructional design, development, and evaluation. She also has more than two decades of experience in e-Learning design and applications. 